\title{
Effect of long-term pore pressure evolution on the integrity of cement plugs of abandoned oil wells in CCS sites
}

\author{
Ariadna Martínez*, Joaquín Liaudat ${ }^{\dagger}$, Carlos López* and Ignacio Carol* \\ * ETSECCPB (School of Civil Engineering) \\ Universitat Politècnica de Catalunya (UPC) \\ Campus Nord UPC, 08034 Barcelona \\ E-mail: ariadna.martinez.e@upc.edu, carlos.maria.lopez@upc.edu, ignacio.carol@upc.edu
}

${ }^{\dagger}$ Faculty of Civil Engineering and Geosciences

Delft University of Technology

2628 CN Delft, The Netherlands

E-mail: j.liaudat@tudelft.nl

\begin{abstract}
In Carbon Capture Storage (CCS) sites, an important element of risk to be considered is the integrity of the cement seals of the abandoned wells in the reservoir [1]. The main goal of abandonment procedure once the life of a well is completed is to provide an effective isolation of the reservoir fluids in order to reduce environmental risk of contamination. In the case that the site has been reconverted to $\mathrm{CCS}$, this is even more essential to prevent $\mathrm{CO}_{2}$ leaks from the storage site. It is important to note that the cracking conditions of the well cement seal can be affected by the long term changes in pore pressures that take place after the oil exploitation activities have stopped [2]. For example, slow pressure return around extraction wells (where the pore pressure had been subject to a sustained reduction during long extraction periods) may cause a progressive reduction of the effective stresses acting on the cement casing and plug, while the opposite can happen at injection wells. And these effects may be partially modified by the overall structural response due to the volume changes implied by the effective stress changes [3].

In this paper, a preliminary study of the effects of such stress changes on the potential integrity of a $2 \mathrm{D}$ cross-section of the sealed oil well system (caprock-external cement sheath-steel casingcement plug) during its service-life (injection/production activities and abandonment) has been performed by means of FE method including zero-thickness interface elements to represent potential cracks. In particular, these elements are pre-inserted in the analysis in between the contacts of caprock-external cement sheath, external cement sheath-casing and casing-cement plug. The results presented show that, depending on the initial state and range of pressure evolution, the different interfaces considered may open or close in a non-trivial manner during the pressure return process. This seems to indicate the importance of considering carefully the pressure return process and subsequent effective stresses evolution in abandoned reservoirs recycled to CCS, in order to avoid that new cracks in well cement seals may lead to potential $\mathrm{CO}_{2}$ leakage in the storage site.
\end{abstract}

\section{REFERENCES}

[1] S.E. Gasda, S. Bachu, M.A. Celia, The potential for $\mathrm{CO}_{2}$ leakage from storage sites in geologica media; analysis of well distribution in mature sedimentary basins, Environmental Geology 46 (6-7) (2004) 707-720.

[2] M. Mainguy, P. Longuemare, A. Audibert, E. Lécolier, Analyzing the risk of well plug failure after abandonment, Oil \& Gas Science and Technology-Revue de l'IFP 62 (3) (2007) 311-324.

[3] J. Rutqvist, D.W. Vasco, L. Myer, Coupled reservoir-geomechanical analysis of $\mathrm{CO}_{2}$ injection and ground deformations at in Salah, Algeria, International Journal of Greenhouse Gas Control, 4 (2) (2010) 225-230. 